\title{
Young Man with Hodgkin Disease with Skin Rash
}

A 34-year-old male diagnosed with Hodgkin's lymphoma on ABVD chemotherapy (it includes the drugs doxorubicin hydrochloride [adriamycin], bleomycin sulfate, vinblastine sulfate, and dacarbazine) presented with pruritic skin lesions - which changed color from reddish to dark hyperpigmented ones over 10 days - not responding to topical steroids or antihistamines [Figure 1]. The second course presented with worse reactions, which got better after cold packing over the rashes before chemotherapy.

\section{What Is the Diagnosis?}

\section{Answer}

Bleomycin-induced flagellate erythema.

This is a rare condition where a typical "whip lash" appearance is seen (classic rash with intermingled lacy appearance). One of the postulated mechanisms is lack of bleomycin-hydrolase, making the skin a vulnerable site for the same. Other mechanisms may include localized increase in melanogenesis, pigmentary incontinence secondary to inflammation, alterations in normal pigmentation patterns besides the bleomycin itself. Symptomatic care in the form of antihistamines and topical steroids suffices in cases where the rash does not resolve spontaneously. Heat in an area previously affected by flagellate erythema has caused recurrence, called heat-induced recall. Therefore, cooling before chemotherapy administration might prevent it. Severe rash requires discontinuation of bleomycin. ${ }^{[1]}$

\section{Declaration of patient consent}

The authors certify that they have obtained all appropriate patient consent forms. In the form the patient(s) has/have given his/her/their consent for his/her/their images and other clinical information to be reported in the journal. The patients understand that their names and initials will not be published and due efforts will be made to conceal their identity, but anonymity cannot be guaranteed.

Financial support and sponsorship

Nil.

\section{Conflicts of interest}

There are no conflicts of interest.

\section{Suresh VS Attili ${ }^{1}$, Janarthan Babu ${ }^{2}$, V Nishit ${ }^{1}$ \\ ${ }^{1}$ Department of Medical Oncology, Omega Hospital, ${ }^{2}$ Department of Medical Oncology, AIG Hospital, Hyderabad,} Telangana, India

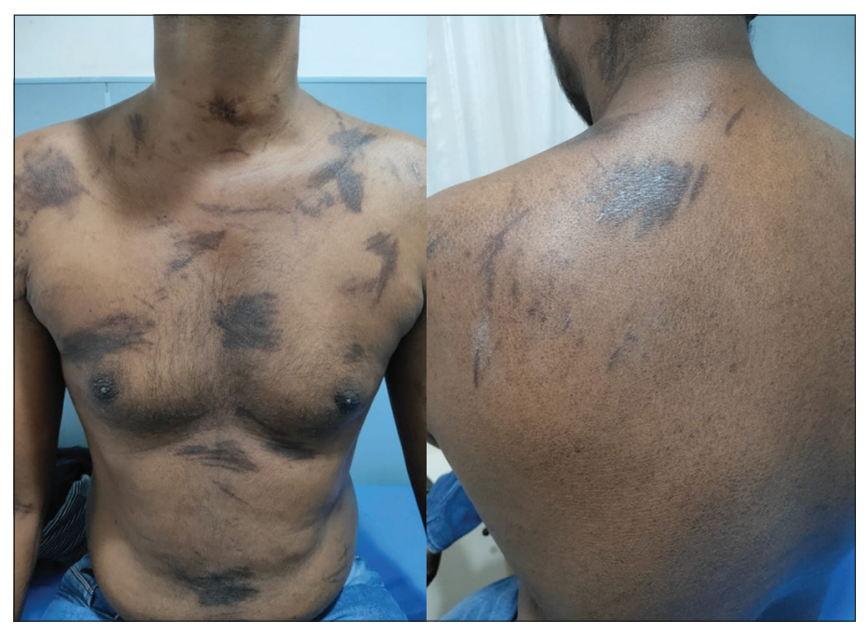

Figure 1: Skin lesions look like below - which are predominantly over the trunk - sparing the limbs and face having whip lash appearance

\section{Address for correspondence: Dr. Suresh VS Attili, Department of Medical Oncology, Omega Hospital, Hyderabad - 500 034, Telangana, India. \\ E-mail: attilivss@gmail.com \\ Submitted: 24-Dec-2019 \\ Accepted in Revised Form: 06-Jan-2020 \\ Published: 17-Feb-2020}

\section{Reference}

1. Changal KH, Raina $\mathrm{H}$, Changal $\mathrm{QH}$, Raina $\mathrm{M}$. Bleomycin-induced flagellate erythema: A rare and unique drug rash. West Indian Med J 2014;63:807-9.

This is an open access journal, and articles are distributed under the terms of the Creative Commons Attribution-NonCommercial-ShareAlike 4.0 License, which allows others to remix, tweak, and build upon the work non-commercially, as long as appropriate credit is given and the new creations are licensed under the identical terms.

\begin{tabular}{|l|l|}
\hline \multicolumn{2}{|c|}{ Access this article online } \\
\hline Quick Response Code: & Website: \\
\hline & www.ijmpo.org \\
\cline { 2 - 2 } & Dol: \\
\hline
\end{tabular}

How to cite this article: Attili SV, Babu J, Nishit V. Young man with hodgkin disease with skin rash. Indian J Med Paediatr Oncol 2019;40:565. 